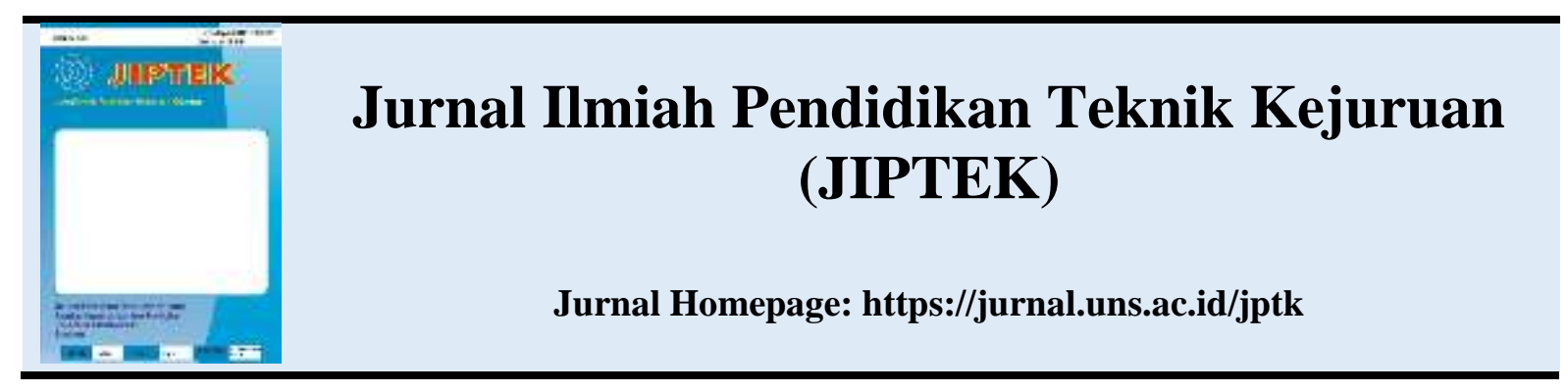

\title{
ANALISIS PERBANDINGAN BIODIESEL MINYAK SAWIT, MINYAK BIJI KEPUH DAN MINYAK JELANTAH TERHADAP EMISI GAS BUANG DAN OPASITAS PADA MESIN DIESEL
}

\author{
Dinadha Aries Wahyudi, Ranto, Basori \\ Program Studi Pendidikan Teknik Bangunan, Universitas Sebelas Maret \\ E-mail: wahyudiaries.wa@gmail.com
}

\begin{abstract}
The purpose of this research are: (1) Proving which biodiesel is better in reducing the opacity of exhaust gas in diesel engine. (2) Proves which biodiesel is better at reducing CO exhaust emissions in diesel engines. (3) Proves which biodiesel is better at reducing $\mathrm{HC}$ exhaust emissions on diesel engines. Research method using experiment method. Populations derived from variants of biodiesel used with the sample of palm oil biodiesel, Kepoh seed oil and waste cooking oil. Samples are mixed with pure diesel oil with a concentration of 20\% (B20) of each biodiesel with diesel sold in the market. The research data is taken from the measurement of exhaust emission and opacity through print out of emission test equipment. Based on the results of this study it can be concluded that: (1) Mixture B2O seed oil has the lowest level of CO emissions. (2) Mixture B2O seed oil has the lowest level of HC gas emissions. (3) The B20 mixture of pure seed oil becomes the mixture having the most lace opacity content with an average decrease of $26 \%$.
\end{abstract}

Key Words : palm oil biodiesel, Kepoh seeds oil biodiesel, waste cooking oil biodiesel, CO HC gas emissions, opacity, addition of B20 mixture

\begin{abstract}
Abstrak
Tujuan penelitian ini adalah : (1) Membuktikan biodiesel manakah yang lebih baik dalam mengurangi opasitas gas buang pada mesin diesel. (2) Membuktikan biodiesel manakah yang lebih baik dalam mereduksi emisi gas buang CO pada mesin diesel. (3) Membuktikan biodiesel manakah yang lebih baik dalam mereduksi emisi gas buang HC pada mesin diesel. Metode penelitian menggunakan metode eksperimen. Populasi diambil dari varian biodiesel yang digunakan dengan sampel yaitu biodiesel minyak sawit, minyak biji kepuh dan minyak jelantah. Sampel dicampur minyak solar murni dengan konsentrasi 20\% (B20) dari masing-masing biodiesel dengan solar yang terjual dipasaran. Data penelitian diambil dari hasil pengukuran emisi gas buang serta opasitas melalui hasil print out cetakan alat uji emisi. Berdasarkan hasil penelitian dapat disimpulkan bahwa : (1) Campuran B20 minyak biji kepuh memiliki tingkat emisi gas CO paling rendah. (2) Campuran B20 minyak biji kepuh memiliki tingkat emisi gas HC yang paling rendah. (3) Campuran B20 minyak biji kepuh menjadi campuran yang memiliki kadar opasitas paling renda dengan penurunan rata-rata sebesar $26 \%$.
\end{abstract}

Kata Kunci : biodiesel minyak sawit, biji kepuh, minyak jelantah, emisi gas CO HC, opasitas, campuran B20. 


\section{Pendahuluan}

Kebutuhan energi dalam memenuhi kebutuhan manusia akan terus meningkat seiring kemajuan zaman. Bahan bakar fosil menjadi salah satu energi utama yang menopang kehidupan manusia baik dalam keseharian maupun di dunia industri, akan tetapi cadangan bahan bakar fosil tersebut dari tahun ke tahun akan terus mengalami penipisan jumlah. Hal tersebut menjadi permasalahan yang nyata dan memerlukan solusi yang relevan mengingat kebutuhan akan sumber bahan bakar yang terus meningkat dari tahun ke tahun.

Berdasarkan data ESDM (2016), total konsumsi bahan bakar minyak (BBM) Indonesia pada tahun 2016 mencapai 69 juta kilo liter yang terdiri dari solar sebesar 14,9 juta kilo liter, BBM penugasan khusus (Premium di luar Jawa, Madura dan Bali) sebesar 12,2 juta kilo liter dan BBM umum lainnya sebesar 42,4 juta kilo liter. Namun bahan bakar minyak yang ada saat ini masih menggunakan minyak bumi yang jika digunakan dapat mencemari lingkungan terkhusus pada pencemaran udara. Maka dari itu penting untuk menghindari pencemaran udara dengan pencegahan dan penanggulangan dari sumber pencemarannya.

Di Indonesia sekarang ini kurang lebih $70 \%$ pencemaran udara di sebabkan emisi kendaraan bermotor yang mengeluarkan zat-zat berbahaya yang dapat menimbulkan dampak negatif, baik terhadap kesehatan manusia maupun terhadap lingkungan, seperti timbal/timah hitam $(\mathrm{Pb})$ kendaraan bermotor menyumbang hampir $100 \%$ timbal. (Sugiarti, 2009, p.51). Emisi gas buang pada peralatan yang berbahan bakar minyak memang masih menjadi pokok masalah pada pencemaran lingkungan terkhusus pada mesin diesel yang jika ditinjau lebih banyak menghasilkan asap yang pekat. Asap pekat ini yang disebut dengan opasitas, semakin besar tingkat opasitasnya semakin besar efeknya terhadap lingkungan.

Salah satu solusi untuk mengurangi pencemaran yaitu dengan penggunaan bahan bakar nabati yang ramah lingkungan Penggunaan bahan bakar minyak nabati ini disebut sebagai biofuel. Biodiesel merupakan biofuel yang diperuntukkan mesin-mesin diesel. Selain itu menurut beberapa penelitian yang telah dilakukan Hwai Chyuan dkk, 2013: 245 menyatakan bahwa angka setana pada pembuatan biodiesel yang mereka buat menghasilkan angka sebesar 56,5. Angka setana dari temuan riset tersebut membuktikan bahwa biodiesel memiliki angka setana lebih besar dari pada bahan bakar solar yang hanya berkisar 40. Angka setana merupakan ukuran yang menunjukkan kualitas dari bahan bakar untuk diesel. Penggunaan biodiesel dengan angka setana yang lebih tinggi jika dibandingkan dengan solar akan berdampak baik terhadap karakteristik emisi yang dihasilkan.

\section{Metode Penelitian}

Penelitian ini merupakan jenis penelitian kuantitatif eksperimen. Pengujian emisi gas buang mengacu pada SNI 09-7118.3-2005 untuk pengujian emisi gas $\mathrm{CO}$ dan $\mathrm{HC}$ serta SNI 09-7118.3-2005 untuk pengujian opasitas gas buang dari Badan Standardisasi Nasional (BSN) Pelaksanaan eksperimen dilakukan di Laboratorium Otomotif Program Studi Pendidikan Teknik Mesin FKIP UNS Surakarta dengan menggunakan alat Gas Analyzer serta Smokemeter.

Populasi dalam penelitian ini adalah varian bahan bakar biodiesel dengan sampel yaitu bahan bakar biodiesel minyak sawit, minyak biji kepuh dan minyak jelantah. Biodiesel sampel dicampur minyak solar murni dengan konsentrasi 20\% (B20) dari masingmasing biodiesel dengan solar yang terjual dipasaran.

Data penelitian diambil dari hasil pengukuran emisi gas buang serta opasitas menggunakan alat gas analyzer dan smoke analyzer yang akan diketahui nilai emisi gas CO HC serta kadar opasitas gas buang dari hasil print out cetakan alat uji emisi.

Hasil pengujian kemudian akan dikonversi ke dalam diagram dan dianalisis menggunakan teknik analisis data deskriptif komparatif. 


\section{Prosedur Penelitian}

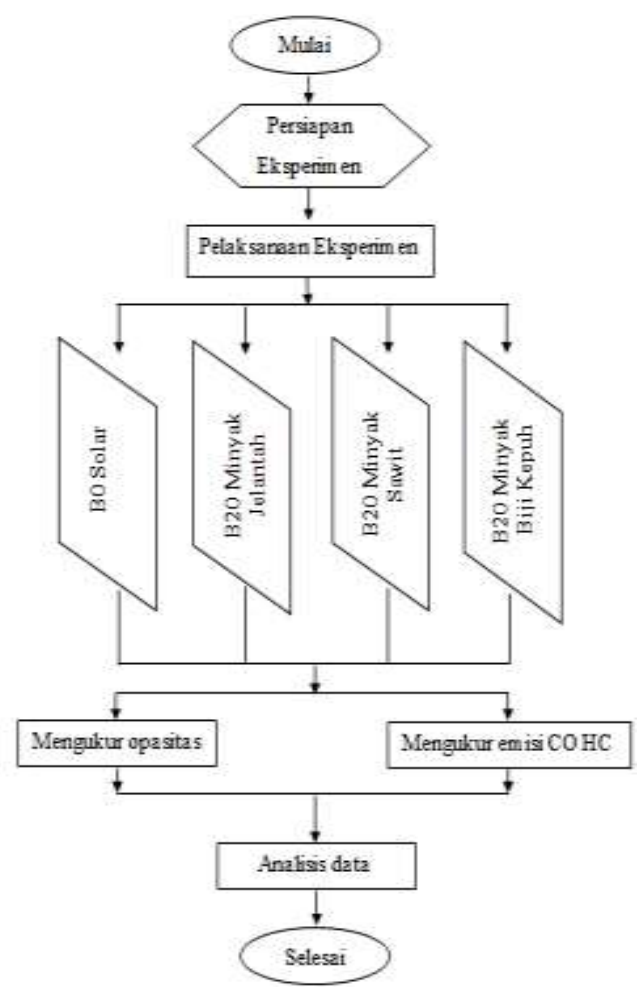

Gambar 1. Prosedur Penilitian

\section{Pembahasan}

\section{Emisi Gas CO}

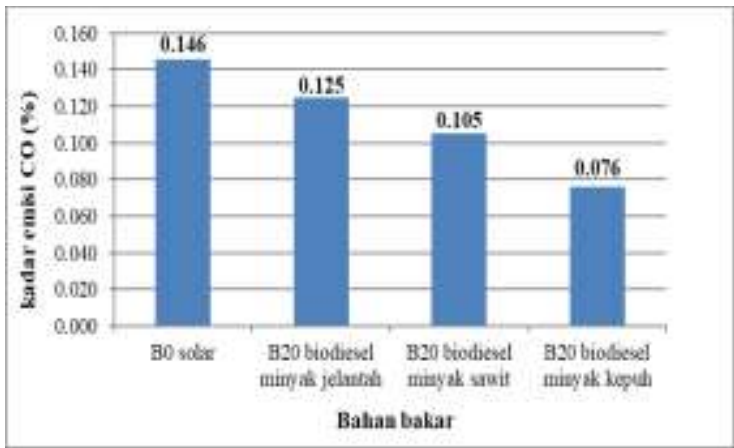

Gambar 2. Diagram Perbandingan Emisi Gas Buang CO Mesin Diesel

Pada gambar 1. diagram menunjukan hasil pengujian tiap campuran bahan bakar B20. B20 minyak kepuh menjadi bahan bakar yang memiliki hasil paling rendah, kemudian B20 minyak sawit, B20 minyak jelantah. Diantara campuran bahan bakar, B20 minyak kepuh memiliki kemampuan paling baik dalam mereduksi emisi gas karbonmonoksida yaitu dengan angka penurunan sebesar $47,94 \%$ kemudian B20 minyak sawit dengan 28,08\% dan B20 minyak jelantah $14,38 \%$, hal ini dikarenakan karena B20 minyak kepuh memiliki kandungan oksigen tinggi yang dapat memenuhi kekurangan asupan oksigen selama pembakaran di dalam mesin dan memiliki indeks angka setana yang cukup tinggi sehingga B20 minyak kepuh menjadi campuran bahan bakar dengan kemampuan lebih unggul dari campuran bahan bakar lainnya. (Chyuan, 2013, p.975) menunjukkan bahwa biodiesel minyak biji kepuh memiliki kandungan oksigen $11,68 \%$ dan angka setana campuran B20 sebesar 52,7. (Acevedo, 2011, p.154) dalam penelitiannya menjelaskan mengenai biodiesel minyak sawit memiliki kandungan oksigen sebanyak $11,7 \%$ serta dalam penelitian. (Mosarof, 2016, p.123) mengemukakan bahwa campuran B20 minyak sawit memiliki indeks setana sebesar 49,2. Penelitian terkait campuran bahan bakar minyak sawit dijelaskan dalam (Attia, 2015, p.5) bahwa biodiesel minyak jelantah memiliki kandungan oksigen 7,3\% serta angka setana sebesar 49 .

\section{Emisi Gas HC}

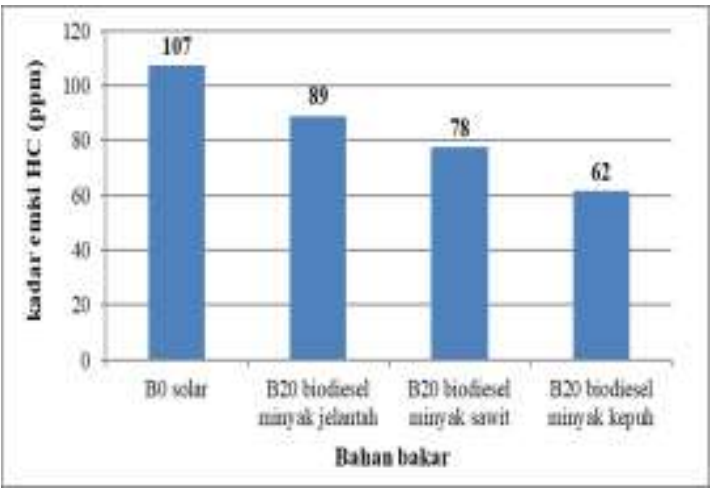

Gambar 3. Diagram Perbandingan Emisi Gas Buang HC Mesin Diesel

Pada diagram hasil pengujian bahan bakar terhadap emisi gas buang hidrokarbonnya (HC) pada mesin diesel B20 minyak biji kepuh menjadi bahan bakar dengan hasil uji emisi $\mathrm{HC}$ yang paling rendah dengan penurunan $42,05 \%$, B20 minyak sawit dengan $27,10 \%$ dan B20 minyak jelantah dengan $16,82 \%$. Campuran B20 minyak kepuh memiliki Kandungan oksigen serta angka setana dalam bahan bakar yang tinggi seperti yang telah dikemukakan sehingga mempengaruhi kadar emisi gas HC. Hal tersebut sejalan dengan (Mosarof, 2016, p.126) yang menunjukkan bahwa kadar emisi gas HC disebabkan oleh kadar kandungan oksigen dalam bahan bakar dan jumlah angka setana yang lebih tinggi. Selain kandungan 
oksigen serta angka setana (Devan, 2009, p.517).

\section{Opasitas Gas Buang}

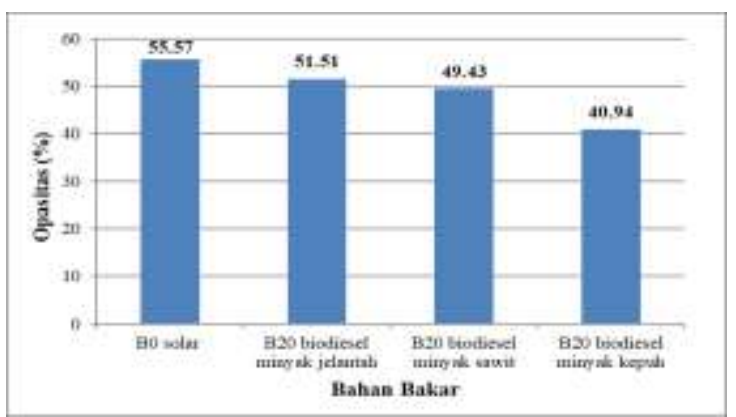

Gambar 4. Diagram Perbandingan Opasitas Gas Buang Mesin Diesel

Gambar 3 diagram menunjukan adanya hasil yang positif artinya adanya penurunan kadar nilai opasitas dalam penggunaan berbagai jenis biodiesel. Penurunan opasitas yang paling signifikan terjadi pada campuran B20 menggunakan biodiesel minyak biji kepuh, yaitu terjadi penurunan kadar nilai opasitas rata-rata sebesar $26 \%$. Laju penurunan kadar nilai opasitas mulai dari B0, B20 minyak jelantah dan B20 minyak sawit menunjukan angka yang hampir stabil serta perolehan angka prosentasi yang dihasilkan masih dalam kisaran yang tidak jauh berbeda. (Enweremadu, 2010, p.2869) menjelaskan bahwa kepekatan asap sangat bergantung pada jumlah udara di dalam silinder serta pada jumlah oksigen dalam bahan bakar. Jelas bahwa komposisi bahan bakar mempengaruhi jumlah asap yang dihasilkan oleh mesin.. (Sivaramakrishnan, 2012, p.205) dalam penelitiannya menunjukkan bahwa biodiesel merupakan bahan bakar yang tidak mengandung sulfur dan memiliki $10-12 \%$ kandungan oksigen yang dapat mereduksi emisi serta kepekatan gas buang mesin diesel. Angka setana juga dapat mempengaruhi proses pembakaran serta kepekatan gas buang yang dihasilkan. B20 minyak kepuh memiliki kandungan angka setana yang lebih tinggi jika dibandingkan dengan ketiga bahan bakar lainnya sehingga mempengaruhi opasitas gas buang yang dihasilkan.

\section{Kesimpulan}

Berdasarkan hasil penelitian, analisa dan pembahasan yang sudah dilaksanakan yaitu mengenai uji perbandingan campuran bahan bakar biodiesel minyak sawit, biodiesel minyak jelantah dan biodiesel minyak biji kepuh dengan bahan bakar solar maka dapat disimpulkan beberapa hal sebagai berikut :

1. Campuran B20 minyak biji kepuh menjadi campuran yang memiliki uji emisi gas buang yang paling baik dalam emisi gas $\mathrm{CO}$ kemudian berturut-turut campuran B20 minyak sawit dan campuran B20 minyak jelantah.

2. Campuran B20 minyak biji kepuh menjadi campuran yang memiliki uji emisi gas buang yang paling baik dalam emisi gas HC kemudian berturut-turut campuran B20 minyak sawit dan campuran B20 minyak jelantah.

3. Campuran B20 minyak biji kepuh menjadi campuran yang memiliki uji opasitas paling baik dalam mereduksi kadar nilai opasitas gas buang kemudian campuran B20 minyak sawit dan yang terakhir yaitu pada campuran B20 minyak jelantah. Penurunan opasitas paling signifikan terjadi pada campuran B20 minyak biji kepuh yaitu terjadi penurunan kadar nilai opasitas rata-rata sebesar $26 \%$.

Setelah serangkaian hasil pengujian dan analisis data yang telah dilakukan maka dapat diberikan saran untuk penelitian selanjutnya sebagai berikut:

1. Bagi pengguna kendaraan ataupun alat khususnya yang menggunakan mesin diesel maka penggunaan biodiesel minyak biji kepuh sebagai alternatif campuran bahan bakar sangat disarankan agar dapat mengurangi polusi udara. 2. Penelitian ini menghasilkan hasil yang positif untuk mereduksi kadar nilai opasitas serta emisi gas buang mesin diesel sehingga diharapkan penelitian lanjutan terkait bahan bakar alternatif biodiesel lainnya dapat ditindak lanjuti lebih luas.

3. Untuk pengembangan lebih lanjut, dapat dilakukan dengan menguji efek penggunaan campuran biodiesel terhadap performa mesin diesel.

4. Penelitian selanjutnya diharapkan mampu menggunakan mesin-mesin diesel yang lebih modern untuk melihat seberapa efektifkah penggunaan biodiesel diera mesin modern seperti sekarang ini.

\section{Daftar Pustaka}

Acevedo, Helmer. (2011). Performance and Emission of A Heavy Duty Diesel Engine Fuelled with Palm Oil Biodiesel and 
Premium Diesel. International Journal of Scientific Vol. 78, No. 170.

Attia, Ali M.A. \& Hassaneen, Ahmad E. (2015). Influence of Diesel Fuel Blended with Biodiesel Produced from Waste Cooking Oil on Diesel Engine Performance. International Journal of Science

Biodiesel Handling and Use Guidelines. (2006). Oak Ridge: U.S. Department of Energi.

Djamin, Martin; S. Wirawan, Soni. (2010). Pengaruh Komposisi Biodiesel terhadap Kinerja Mesin dan Emisi Gas Buang. Hasil Penelitian Pusat Pengkajian dan Penerapan Teknologi Konversi dan Konservasi Energi dan Balai Rekayasa Desain dan Sistem Teknologi Badan Pengkajian dan Penerapan Teknologi Tahun 2010, Hlm. 381-387. Jakarta.

Enweremadu, C.C; L. Rutto H. (2010). Combustion, Emission and Engine Performance Characteristics of Used Cooking Oil Biodiesel. International Journal of Renewable and Sustainable Energy.

Chyuan Ong, Hwai; A.S., Silitonga; H.H., Masjuki; T.M.I. Mahlia; W.T., Chong;
M.H., Boosroh. (2013). Production and Comparative Fuel of Biodiesel from Non-edible oils: Jatropha curcas, Sterculia Foetida and Ceiba Pentandra. International Journal of Energy Conversion and Management, No. 73: 245-255.

Mosarof, H.M, et al. (2016). Optimization of Performance, Emission, Friction, and Wear Characteristics of Palm and Calophyllum Inophyllum Biodiesel Blends. International Journal of Energy Conversion and Management No. 118.

P.K Devan, Mahalakshmi. (2009). Performance, Emission, and Combustion Characteristics of Poon Oil and its Diesel Blend in a DI Diesel Engine. International Journal of Fuel Processing Technology, No. 90.

Sivaramakrishnan, K. (2012). Determination of Cetane Number of Biodiesel and It's Influence on Physical Properties. International Journal of Engineering and Applied Sciences. Vol. 7, No. 2.

Sugiarti. (2009). Gas Pencemar Udara dan Pengaruhnya bagi Kesehatan Manusia. Jurnal of Chemica, Vol. 10, No. 1. 